\title{
PEMANFAATAN INSTAGRAM BUSINESS SEBAGAI STRATEGI PROMOSI PRODUK PADA AHASS ZAMRUD MOTOR
}

\author{
Galuh Krisna Dewanti ${ }^{1}$, Ade Kurnia Solihin ${ }^{2}$ \\ Teknik Industri, Fakultas Teknik dan Ilmu Komputer, Universitas Indraprasta PGRI
}

\begin{abstract}
Abstrak
Kemampuan interaktif dimiliki oleh jejaring sosial seperti Instagram dan jejaring sosial lain, ini lah yang membuat media online lebih unggul lagi dibanding media tradisional yang hanya bersifat satu arah dalam menyampaikan pesan komunikasinya. Sedangkan media jejaring sosial seperti instagram mampu memberikan feedback secara langsung sehingga tercipta komunikasi antar pribadi. Instagram begitu cepat beradaptasi dengan perkembangan teknologi yang populer ini merupakan nilai tambah bagi Instagram yang lengkap dengan fitur auto reply atau balasan cepat. Beberapa permasalahan yang dihadapi manajemen bengkel AHASS Zamrud Motor Cimanggis adalah kurangnya pengetahuan mengenai strategi promosi produk yang mereka hasilkan dengan menggunakan media sosial bebasis internet dan kurangnya keinginan manajemen bengkel untuk mengembangkan potensi yang mereka miliki mengenai media sosial berbasis online. Pelaksanaan Kegiatan pengabdian kepada masyarakat ini dilakukan dalam tiga tahap, yaitu: tahap persiapan, pelaksanaan, dan evaluasi. Pelaksanaan pengabdian masyarakat dilakuakn bersama manajemen bengkel AHASS.
\end{abstract}

Kata Kunci: bengkel AHASS, Instagram Bussines, marketing.

\begin{abstract}
Interactive capabilities possessed by social networks like Instagram and other social networks, this is what makes online media superior to traditional media which is only oneway in delivering communication messages. Whereas social networking media like Instagram can provide direct feedback so as to create interpersonal communication. Instagram is so quick to adapt to the development of this popular technology that is a plus for Instagram, complete with auto reply feature or fast reply. Some of the problems faced by AHASS Zamrud Motor Cimanggis workshop management are the lack of knowledge about the product promotion strategies they produce using internet-based social media and the lack of workshop management's desire to develop the potential they have about online-based social media. Implementation Community service activities are carried out in three stages, namely: the preparation, implementation and evaluation stages. Implementation of community service is carried out together with AHASS workshop management.
\end{abstract}

Keywords: AHASS workshop, Instagram Bussines, marketing.

Correspondence author: Galuh Krisna Dewanti, galuhdewanti@gmail.com, Jakarta, Indonesia

This work is licensed under a $C C-B Y-N C$

\section{PENDAHULUAN}

Evolusi teknologi media terjadi pada zaman digital sekarng ini, orang biasanya menyebut dengan media online atau internet, Di negara maju, media online mengalahkan 
berbagai media yang sebelumnya telah dijadikan sumber referensi dalam mendapatkan sebuah informasi.

Istilah new media muncul akibat kehadiran internet, new media adalah semua media yang telah dipengaruhi oleh teknologi. istilah new media digunakan untuk menyebut media jenis baru yang menggabungkan antara media konvensional dengan media internet. Perkembangan teknologi informasi yang terjadi memunculkan istilah ECommerce yaitu proses pembelian dan penjualan produk, jasa dan informasi yang dilakukan secara elektronik dengan menggunakan jaringan komputer dan jaringan yang digunakan adalah jaringan internet (Morissan, 2010).

Internet merupakan jaringan besar yang dibentuk oleh inter koneksi jaringan komputer dan komputer tunggal di seluruh dunia lewat saluran telepon, satelit, dan sistem telekomunikasi lainnya (Anastasa, 2001). Pemanfaatan social media dapat berimbas positif bagi pencitraan obyek atau destinasi wisata (Ellya, 2015).

Peluang dan tantangan dalam melakukan komunikasi pemasaran internet menjadikan sebuah gebrakan baru dalam dunia pemasaran produk ataupun jasa. Media interaktif memungkinkan terjadinya arus informasi timbal balik yang memungkinkan pengguna dapat berpartisipasi dan memodifikasi isi dari informasi pada saat itu juga (real time) (Morissan, 2010). Kemampuan interaktif yang dimiliki oleh jejaring sosial seperti Instagram dan jejaring sosial lain, ini lah yang membuat media online lebih unggul lagi dibanding media tradisional yang hanya bersifat satu arah dalam menyampaikan pesan komunikasinya. Sedangkan media jejaring sosial seperti instagram mampu memberikan feedback secara langsung sehingga tercipta komunikasi antar pribadi.

Menurut Tjiptono (2008:219) mengemukakan "Promosi pada hakekatnya adalah suatu komunikasi pemasaran, artinya aktifitas pemasaran yang berusaha menyebarkan informasi, mempengaruhi/membujuk, dan atau mengingatkan pasar sasaran atas perusahaan dan produknya agar bersedia menerima, membeli dan loyal pada produk yang ditawarkan perusahaan yang bersangkutan.

Instagram begitu cepat beradaptasi dengan perkembangan teknologi yang populer ini merupakan nilai tambah bagi Instagram yang lengkap dengan fitur auto reply atau balasan cepat. Konsumen suka chatting dengan menanyakan berbagai macam informasi walaupun semua sudah tertera. Kemudian adanya fitur stories dan siaran langsung (live). Konten siaran langsung bisa beragam. Menurut product marketing Manager instagram Business Platform, cerita dibalik layar cukup banyak menarik perhatian pelanggan. Fitur yang tak kalah menarik lagi adalah Tagar (\#). tagar digunakan untuk mempermudah dalam pencarian produk yang dituju. Fakta yang menarik adalah dua dari tiga kunjungan profil instagram bisnis berasal dari non-followers. elanggan/konsumen memanfaatkan tagar atau hastag untuk mencari produk atau jasa yang diincarnya.

Zamrud motor adalah salah satu bengkel resmi dari AHASS. Berada di Jl. Radar AURI. Seiring bertumbuhnya bengkel-bengkel AHASS membuat persaingan semakin ketat. Tak hanya pelayanan saja yang menjadi fokus utama namun juga penjualan sparepart. Bermacam-macam strategi dilakukan untuk mempertahankan eksistensi dalam persaingan pasar. Promosi produk mereka yang berupa pelayanan dan penjualan sparepart tersebut salah satunya bisa menggunakan media online yaitu Aplikasi Instagram.

Sejauh ini pemasaran yang mereka lakukan masih menggunakan pemasaran secara konvensional yaitu dimana pembeli (customer) bertemu secara langsung. Dalam abdimas ini, kami berharap dengan mereka mengetahui cara menggunakan instagram, maka proses pemasaran akan jauh lebih efisien dan efektif. Selain itu, jaungkauan pangsa pasarnya 
pun menjadi tak terbatas, sehingga bisa meningkatkan hasil pelayanan servis maupun penjualan sparepart secara optimal. Namun, kurangnya pengetahuan menjadi hambatan manajemen bengkel tersebut untuk memasarkan produknya melalui media online. Keterbatasan inilah yang menggerakkan kami untuk memberikan wawasan tentang penggunaan media online tersebut. Sekaligus melihat potensi apa lagi yang bisa digali pada masyarakat agar produk-produk mereka bisa dipromosikan secara luas dan merata.

Beberapa permasalahan yang dihadapi oleh bengkel Zamrud Motor adalah sebagai berikut :

1. Kurangnya pengetahuan mengenai strategi promosi produk yang mereka hasilkan dengan menggunakan media sosial bebasis internet.

2. Kurangnya keinginan manajemen bengkel untuk mengembangkan potensi yang mereka miliki mengenai media sosial berbasis online.

\section{METODE PELAKSANAAN}

Metode yang dilakukan dalam kegiatan pengabdian kepada masyarakat ini adalah melalui beberapa tahap:

1. Observasi langsung yaitu: pengabdi langsung datang ke lokasi pengabdiaan untuk memperoleh data. Observasi kami lakukan pada saat menjelang maupun saat kegiatan berlangsung. Observasi dilakukan untuk mengetahui kondisi dan kebutuhan yang diperlukan oleh bengkel AHASS Zamrud Motor Motor terhadap materi yang diperlukan. Pentingnya Observasi yang bertujuan untuk mewujudkan kesuksesan kegiatan pengabdiaan masyarakat itu sendiri.

2. Penyuluhan ini menggunakan teknik penyampaian komunikasi secara interaktif, dimana peserta diberikan informasi tentang konsep keilmuan jenis - jenis media promosi melalui internet yang dapat diterapkan dalam upaya peningkatan daya saing produk kemudian mitra akan berlatih menggunakan media promosi melalui internet serta di tutup dengan sesi tanya jawab antara peserta dan kami sebagai Narasumber atau Pembicara.

Ada tiga tahap dalam Pelaksanaan kegiatan ini yaitu: tahap persiapan, pelaksanaan dan evaluasi. Tahap pertama adalah tahap persiapan, pada tahap ini, team melakukan survei pendahuluan dan wawancara awal terhadap Pimpinan AHASS Zamrud Motor, untuk mengetahui target kegiatan, kondisi karyawan yang akan diberikan pelatihan dan menyusun rancangan kegiatasn yang akan dilakukan. Tahap persiapan selanjutnya, team menyiapkan bahan-bahan yang akan dijadikan pembelajaran sebagai materi pengabdian masyarakat ini.

Tahap kedua yaitu: pelaksanaan, kegiatan pelatihan ini dilakukan team dengan memberikan informasi kepada para karyawan mengenai sosialisasi instagram business untuk menambah wawasan bagi karyawan AHASS Zamrud Motor Cimanggis supaya dapat menggunakan instagram bisnis dengan baik sehingga peserta mendapatkan tambahan wawasan dan pengetahuan mengenai instagram bisnis.

Tahap yang terakhir adalah tahapan evaluasi. Kegiatan evaluasi ini dilakukan terhadap proses kegiatan. Evaluasi proses berkaitan dengan kehadiran peserta, semangat, dan antusias peserta mengikuti kegiatan dan kerja sama yang terjalin selama proses pelaksanaan, serta tingkat pemahaman karyawan untuk penggunaan instagram bisnis.

\section{HASIL DAN PEMBAHASAN}

Sesuai dengan jadwal yang diberi oleh manajemen bengkel AHASS untuk pelaksanaan abdimas adalah tanggal 24 desember dan 31 Desember 2019. Abdimas ini 
diikuti oleh manajemen bengkel. Pelaksanaan abdimas ini diisi dengan pemberian dan penjelasan materi pelatihaan. Materi dijelaskan secara rinci menggunakan bantuan slide presentasi, melalui peragaan visualisasi gambar - gambar serta diskusi, studi kasus sehingga peserta pelatihan dapat lebih mudah memahami materi yang diajarkan. Setelah pemaparan materi, peserta diminta untuk membuka aplikasi Instagram yang telah didownload. Setelah itu masuk ke aplikasi dan masuk pada profil (klik garis 3 diatas), kemudian klik pengaturan/setting. Pilihan ini ada dipojok kanan atas profil anda lalu klik pengaturan. Setelah masuk pengaturan, lalu klik account/akun. Setelah masuk akun, klik ubah jenis akun. Kita pilih "beralih ke akun Bisnis"

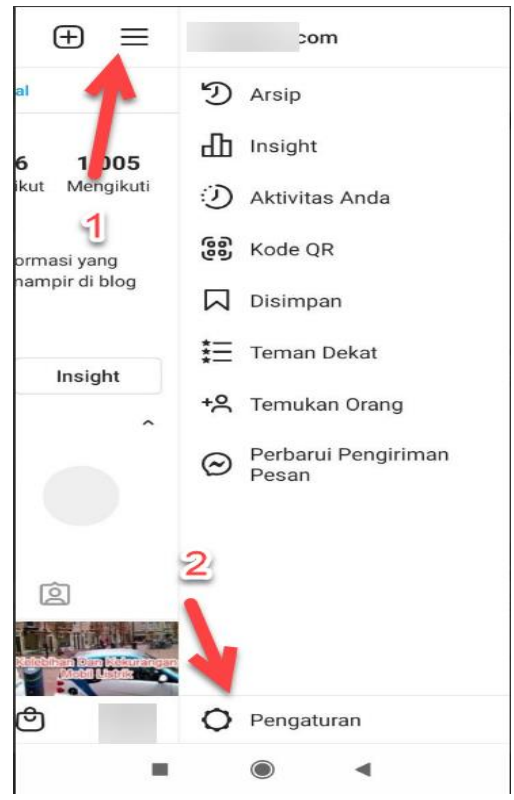

Gambar 1. Halaman muka pengaturan profil Instagram business
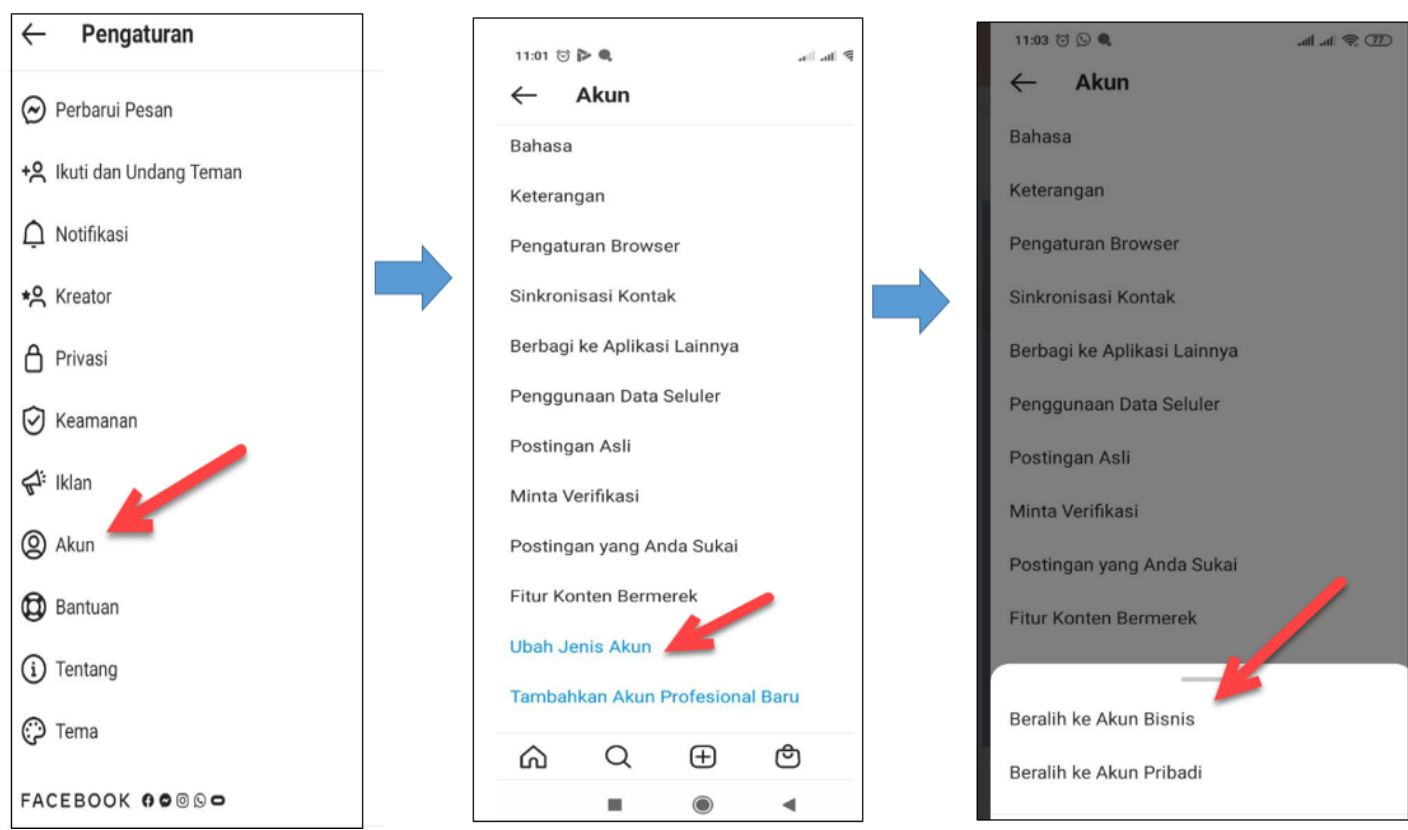

Gambar 2. Pengaturan Account/akun Instagram 
Setelah klik Beralih Kebisnis maka akun anda akan menjadi akun bisnis dengan banyak fitur didalamnya, Tidak usah khawatir anda bisa merubah akun anda menjadi semula kapan saja hal ini sesuia dengan notif yang tampil seperti gambar dibawah ini. Tahap selanjutnya, pada tahapan ini sebenarnya anda di berikan 2 pilihan untuk merubah akun anda menjadi akun bisnis atau akun creator tergantung kebutuhan anda, untuk fitur tidak beda jauh karena kita sedang membahas akun bisnis maka kita pilih akun bisnis.
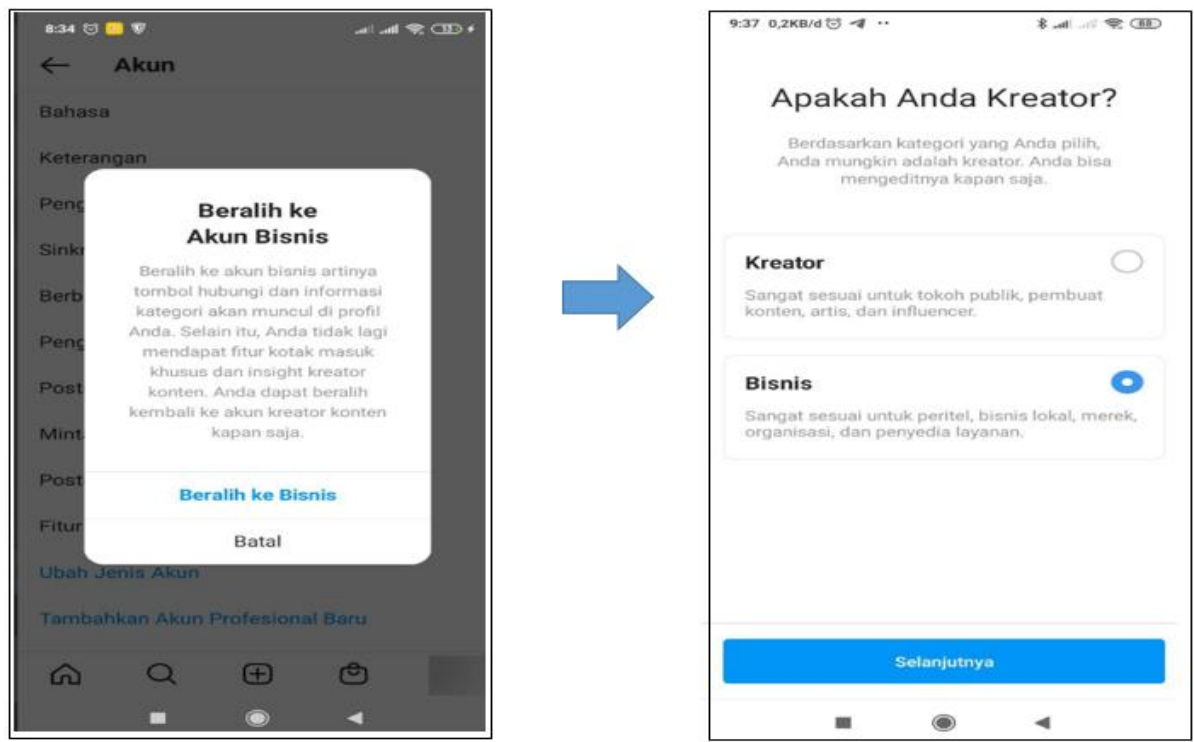

Gambar 4. Pilihan Kreator atau bisnis

Langkah selajutnya adalah kategorikan bisnis yang anda punya dengan memilih kategori yang sudah tersedia, setelah itu anda juga dapat mengintegrasikan instagram bisnis anda dengan akun facebook anda.

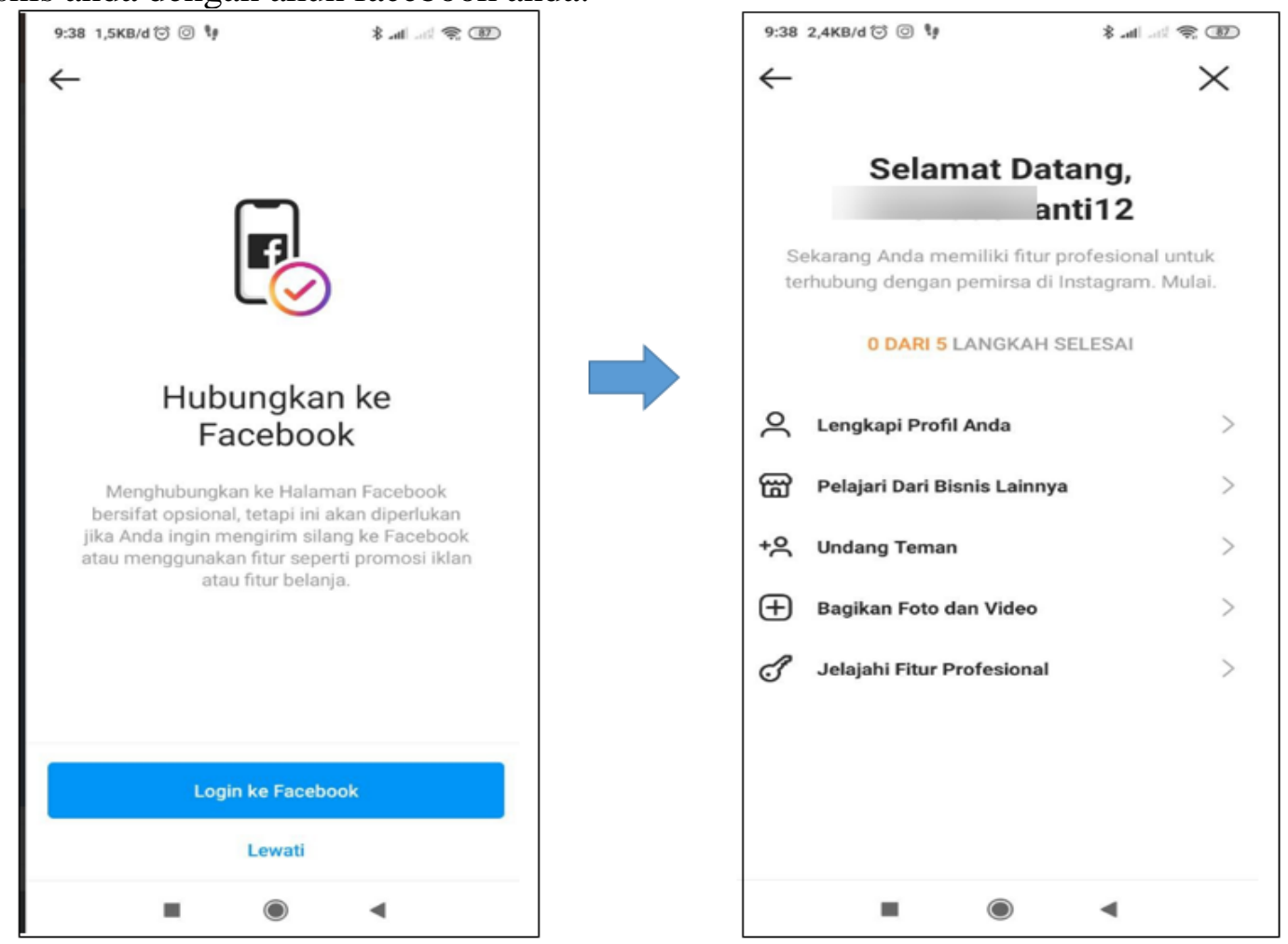

Gambar 5. Akun isntagram bisnis telah jadi 
Kegiatan pelaksanaan pengabdian masyarakat dengan melibatkan Manajemen bengkel Zamrud AHASS, memberikan ilmu pengetahuan yang baru dan antusias manajemen bengkel dalam mengikuti kegiatan ini patut diapresiasi. Dari hasil kegiatan pengabdian masyarakat ini, dapat diketahui materi yang telah disampaikan dimengerti dan bermanfaat bagi manajemen bengkel Zamrud AHASS.

Sebagai penutup kegiatan pengabdian kepada masyarakat, sebelum meninggalkan ruangan tempat pelatihan, foto bersama pun dilakukan sebagai bentuk dokumentasi guna melengkapi lampiran pada laporan kegiatan abdimas.

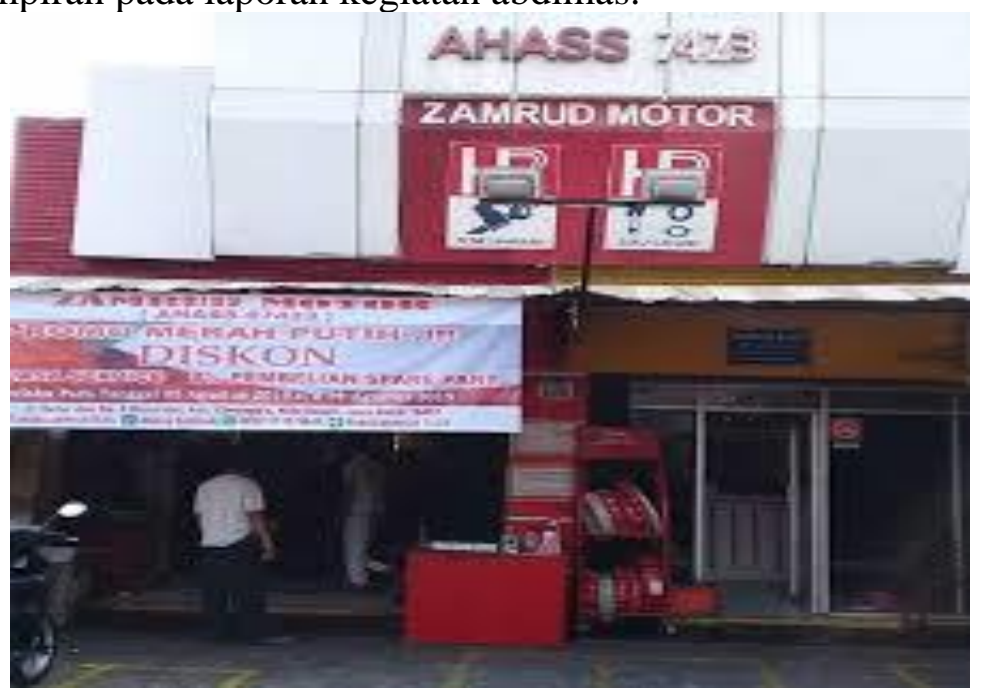

Gambar 6. Lokasi Pengabdian Kepada Masyarakat

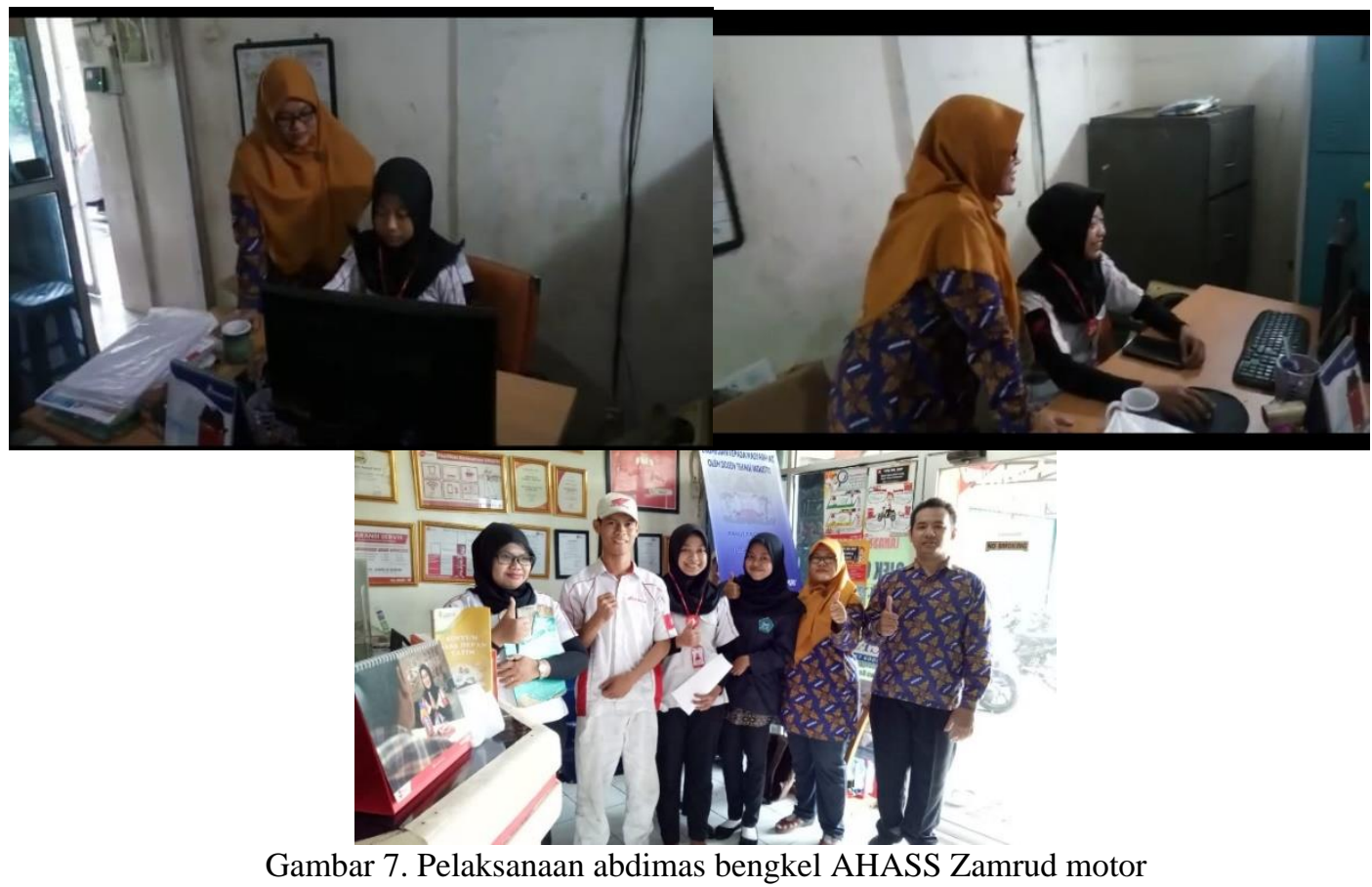

\section{SIMPULAN}

Kegiatan pengabdian masyarakat berjalan dengan lancar dan peserta dapat memahami dengan baik apa yang disampaikan oleh pemateri. Abdimas yang dilakukan ini sangat perlu dan dirasakan manfaatnya oleh Manajemen bengkel AHASS Zamrud 
Motor, karena menambah ilmu dan wawasan, sebagai strategi promosi produk bengkel AHASS Zamrud Motor. Dari simpulan tersebut, team abdimas mengajukan saran dan rekomendasi dalam pelaksanaan pengabdian masyarakat ini, perlu diintensifkan dengan komunikasi yang baik antara pihak manajemen bengkel dengan karyawan sehingga tercipta kondisi kerja yang baik.

\section{DAFTAR PUSTAKA}

A.M, Morissan. 2010. Periklanan komunikasi pemasaran terpadu, Jakarta : Penerbit Kencana.

Diana, Anastasa. (2001). Mengenal E-Business, Edisi Pertama, Cetakan Pertama. Andi, Yogyakarta.

Indika, D., dkk. (2017).Media Sosial Instagram Sebagai Sarana Promosi Untuk Meningkatkan Minat Beli Konsumen. Jurnal Bisnis Terapan. Vol 01, Nomor 01, Juni 2017.

Komarudin, S. (2003). Manajemen Marketing, suatu pendekatan ramuan markeing. Bandung: Angkasa.

Kotler, P (2012) Kotler on Marketing. Simon and Schuster.

Suyanto, M. (2003). Strategi Periklanan pada e-commers perusahaan top dunia. Penerbit Andi.

Tjiptono, Fandy. 2008. Strategi Pemasaran. Andi Offset. Yogyakarta. 